\title{
RELATIONSHIP BETWEEN THE DEVELOPMENT OF DEPTH HOAR AND AVALANCHE RELEASE IN THE TIAN SHAN MOUNTAINS, CHINA*
}

\author{
By MA WeILIN and Hu RuJI
}

(Xinjiang Institute of Geography, Academia Sinica, Urumqi, Xinjiang, China)

\begin{abstract}
In spring and winter, there is a considerable amount of solid precipitation in the western part of the Tian Shan mountains. Avalanches frequently occur here, and often endanger national economic construction and human life. Observation shows that the avalanche occurrences are closely related to the physical characteristics of the snow, especially to the development of depth hoar in the snow cover. The conditions for the development of depth hoar are determined by thickness of the snow cover, air temperature, ground-temperature regime, and the duration of negative temperatures. The results of this study have revealed that the optimum depth of snow cover for the development of depth hoar is about $80 \mathrm{~cm}$ in the Tian Shan mountains, and the mean maximum depth of the snow cover in this region is $78 \mathrm{~cm}$. Therefore, depth hoar develops extraordinarily well. The thickness of depth hoar can reach more than $80 \%$ of the total snow-cover depth. That is one of the main reasons why avalanches still occur frequently under the conditions of a limited snow-cover depth in the western part of the Tian Shan mountains.
\end{abstract}

\section{INTRODUCTION}

The Tian Shan mountains, situated in the central part of Xinjiang, consist of more than 20 mountain ranges with basins and valleys between them. Most of the basins and valleys open mainly toward the west or north-west. This is favourable for water vapour from both the Atlantic Ocean and the Arctic coming direct to the Tian Shan mountains. Because the mountains intercept and capture the water vapour, there is considerable precipitation, especially in the mid-mountain zone of the Tian Shan mountains. Snowfall forms about $30 \%$ of the total precipitation, and provides abundant material for avalanches under the conditions of the favourable topography. Besides the snowfall, the well-developed depth hoar in the snow cover is one of the important factors governing the frequent occurrence of avalanches in the mid-mountain zone of the western Tian Shan mountains. Therefore, it is not only for the theoretical significance for revealing the mechanism of avalanche formation but also for the practical value for forecasting avalanches that the factors and processes influencing the development of depth hoar have been studied.

The fundamental conditions for the development of depth hoar and the relationship between depth hoar and avalanche release are analysed on the basis of the observational data for the temperatures of the ground, snow cover, and air. The reasons for avalanches occurring frequently under the limited thickness of snow cover are also discussed in this paper.

\footnotetext{
* Paper submitted to Symposium on Snow and Glacier Research relating to Human Living Conditions, Lom, Norway, 4 4 September 1988.
}

\section{PRECIPITATION IN THE TIAN SHAN MOUNTAINS}

The precipitation in the western part of the Tian Shan mountains stems mainly from the western and north-western air currents. Although the Atlantic Ocean is far away from Xinjiang, the western wind current of the upper troposphere in Xinjiang is active all year round. Moreover, the water vapour loses little during transport, and is even replenished by the Mediterranean Sea, the Caspian Sea, the Black Sea, the Aral Sea, etc.

There is an abundance of precipitation, especially in the western part of the Tian Shan mountains. According to data collected at the Tian Shan Snow and Avalanche Research Station (i.e. TSAR station, lat. $43^{\circ} 16^{\prime} \mathrm{N}$., long. $84^{\circ} 24^{\prime} \mathrm{E}$; $1776 \mathrm{~m}$ a.s.l.) of the Xinjiang Institute of Geography, Academia Sinica, in the western part of the Tian Shan mountains, the annual precipitation is as much as $827.3 \mathrm{~mm}$, and the maximum is $1139.7 \mathrm{~mm} \mathrm{(1970).} \mathrm{Snowfall}$ in winter accounts for more than $30 \%$ of the annual precipitation, supplying sufficient material for a stable snow cover (Ma Weilin, 1981). The mean and extreme maximum depths of the snow cover are 78 and $149 \mathrm{~cm}$, respectively. Usually, snow accumulation begins in the second $10 \mathrm{~d}$ of October. The maximum of the snow cover which is controlled both by snowfall and air temperature varies from year to year. However, the depth of the snow cover usually increases to a basic value (at least $30 \mathrm{~cm}$ ) for the development of depth hoar by the first $10 \mathrm{~d}$ of December. The stable snow cover disappears in the first or second $10 \mathrm{~d}$ of April, and occasionally in the last $10 \mathrm{~d}$ of March or April, or even the first $10 \mathrm{~d}$ of May.

\section{DEVELOPMENT OF DEPTH HOAR IN THE SNOW COVER}

The main factors influencing the development of depth hoar The essential condition for the development of depth hoar in the snow cover is the temperature gradient which is dependent on the snow-cover depth, air temperature, and ground-temperature regime. Generally speaking, the lower the air temperature and the higher the ground temperature, the larger is the temperature gradient in the snow cover, and correspondingly, the better the depth hoar develops. Consequently, the longer the negative temperature lasts, especially with low temperatures, the thicker the depth hoar will be. According to observations, the temperature in the top $20 \mathrm{~cm}$ of the snow cover is sensitive to fluctuations in the air temperature. So the development of depth hoar needs at least $30 \mathrm{~cm}$ of snow cover because, if the snow cover is thinner, the temperature gradient in the snow cover will be influenced by the fluctuation in the air temperature, and even a positive temperature gradient will appear in the snow cover under conditions of high air temperature. But, if the snow cover is too thick, the gradient will be reduced. Observations show that in the western part of the Tian Shan mountains, when the depth of the snow cover reaches $80 \mathrm{~cm}$, the development of depth hoar speeds up. 
The mean maximum depth of the snow cover is $78 \mathrm{~cm}$ in the area of the Tian Shan Snow and Avalanche Research Station, which closely approximates the optimum depth for the development of depth hoar.

In those areas near the station, the annual mean air temperature is $1.3^{\circ} \mathrm{C}$, and the maximum can reach $32.7^{\circ} \mathrm{C}$. Hence, the ground had already absorbed much heat from the air before the snow season. The snow cover functions as thermal insulation for the ground, so long-wave radiation from the ground to the air is greatly reduced, and the temperature of the ground covered by natural snow cover is much higher than that without a snow cover (Fig. 1). Consequently, the difference between the temperature of the air and that of the ground becomes large (Fig. 2). Thus, a large temperature gradient forms in the snow cover.

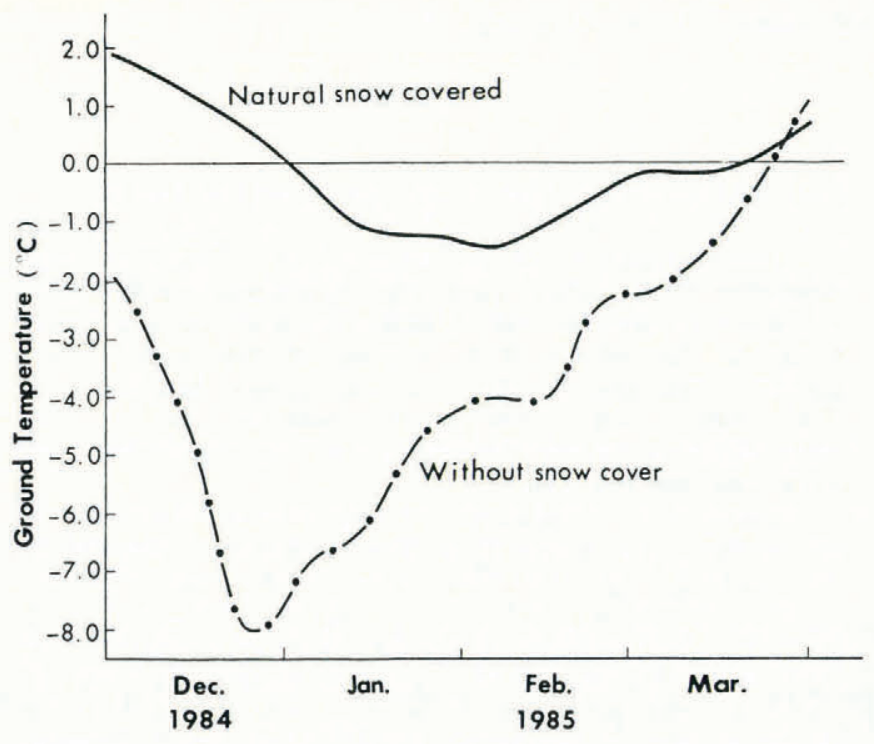

Fig. 1. Comparison of ground temperatures between sites with or without snow cover.

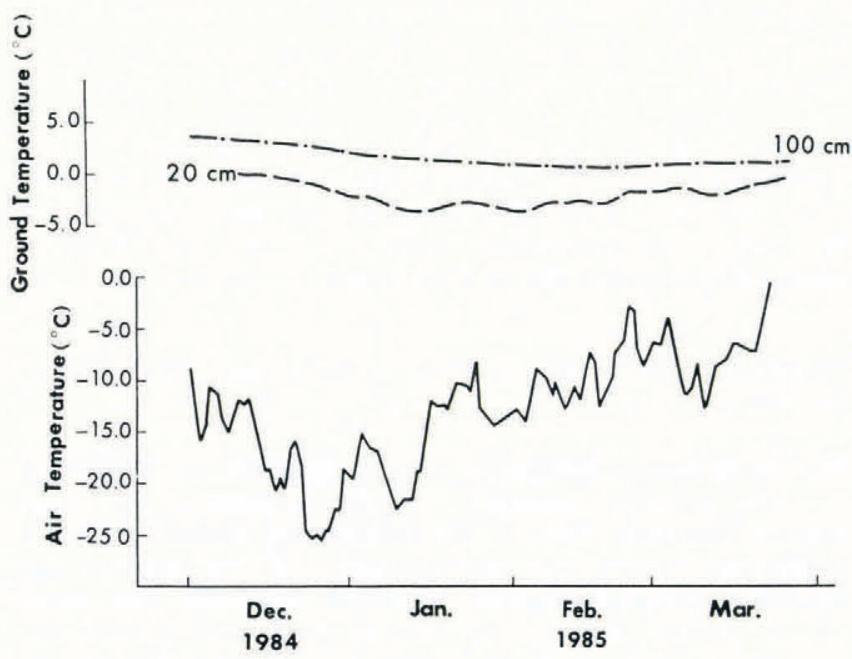

Fig. 2. Comparison of the air and ground temperatures during the snow season.

The conduction of heat between ground, snow cover, and air is also influenced by the characteristics of the snow. In the Tian Shan mountains, the snow has a low water content and density due to the low air temperature (Table I). Therefore, the conduction of heat through the snow cover is low, which is one of the reasons for the large temperature gradient in the snow cover in the western part of the Tian Shan mountains.

The thickness of depth hoar is determined by the duration of negative temperatures which is more than 5 months in the western part of the Tian Shan mountains (Fig. 3), and is sufficient for the development of depth hoar.
TABLE I. DENSITIES OF SEASONAL SNOW COVER IN $\begin{array}{ccc}\text { THE WESTERN } & \begin{array}{c}\text { PART OF THE TIAN SHAN } \\ \text { MOUNTAINS }\end{array}\end{array}$

Snow types

Density

$\mathrm{Mg} / \mathrm{cm}^{3}$

Fresh snow

$0.08-0.14$

Fine-grained snow

$0.12-0.20$

Medium-grained snow

$0.17-0.23$

Coarse-grained snow

$0.20-0.26$

Depth hoar

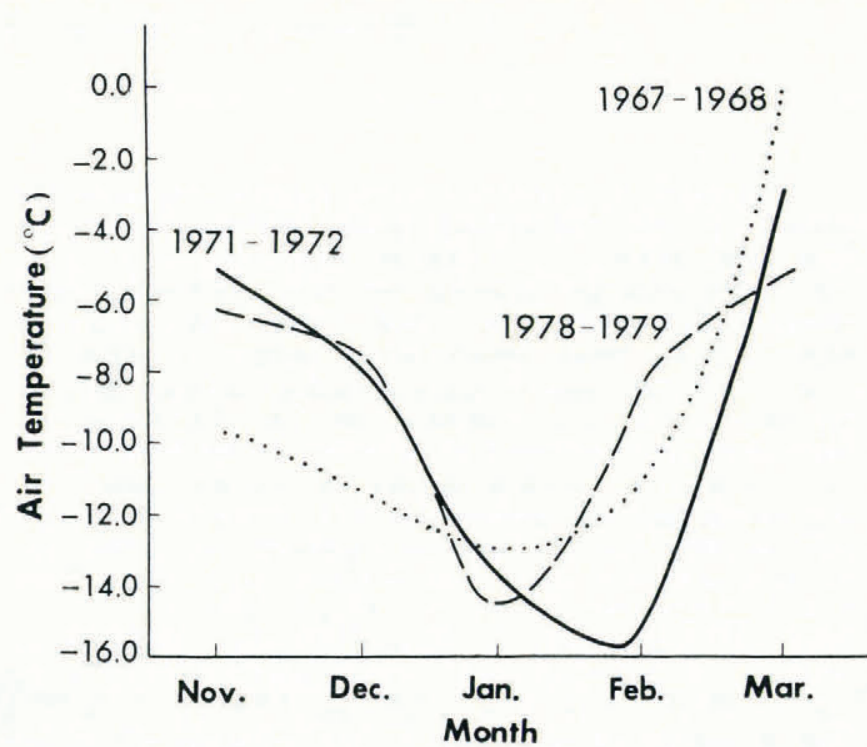

Fig. 3. Monthly mean air temperatures during the snow season of different years at TSAR station.

Development process of depth hoar

The snow cover in the western part of the Tian Shan mountains is seasonal with limited thickness, low density, and low temperature. Therefore, once the snow cover forms, a negative temperature gradient arises and remains in it until the melting season. Owing to this negative temperature gradient, there is a corresponding vapour gradient in the snow cover (Xie Zichu and Ma Zhenghai, unpublished report, 1974). For this reason, the surfaces of snow grains at those places with a lower vapour pressure begin to sublimate, and to condense at places with a higher vapour pressure, that is, vapour is transported from the bottom to the upper layers by the action of the temperature gradient. The course of the sublimation or condensation is the process for the development of depth hoar (Hu Ruji and others, 1985).

Our observations show that the temperature of the snow cover decreases and its temperature gradient increases from December with the decrease of the air temperature. At the same time, the volume of vapour transport increases, and depth hoar develops from the bottom to the upper layers of the snow cover. Because the formation of depth hoar is in its infancy in December, and the natural subsidence and consolidation in the thin snow cover with a low density are weak, the density and hardness of the depth hoar are lower than those of the snow layer above it. If the snow cover reaches more than $50 \mathrm{~cm}$, with the addition of more snowfall, there will be the possibility of avalanches occurring. This is the reason why avalanches occur so easily during this period.

The daily mean air temperature remains between $-10^{\circ}$ and $-25^{\circ} \mathrm{C}$ in December, which causes the average temperature of the snow cover to fall to the lowest point $\left(-10.5^{\circ} \mathrm{C}\right)$, and the average temperature gradient to rise to a maximum value of $0.285 \mathrm{~K} / \mathrm{cm}$. Generally, this is the active period for vapour transport and depth-hoar development. 
The depth hoar might occupy about $50 \%$ of the total snow-cover depth by the end of January. At that time there is a danger of avalanches.

In February, the temperature of the snow cover increases slowly because the weather is becoming warmer, precipitation is less, the weather is fine, and the depth of the snow cover decreases; hence there are fewer avalanches in this period. In 1985, there was an unusual February with much greater snowfall than normal. The monthly snowfall was 4.3 times more than the mean monthly precipitation for February, and the snow-cover depth increased by $80 \mathrm{~cm}$ and reached $142 \mathrm{~cm}$ on 15 February. During snowfall, the average air temperature was as high as $-6.9^{\circ} \mathrm{C}$, resulting in a drop in the negative temperature gradient in the top $80 \mathrm{~cm}$ of snow cover to $0.064 \mathrm{~K} / \mathrm{cm}$ and the occurrence of a positive temperature gradient at $80-100 \mathrm{~cm}$ depth. Therefore, the speed of the development of depth hoar decreased, and so did the relative thickness of depth hoar.

From March to early April, the weather alternated between cold and warm with a trend towards warming, and temperatures of the ground and snow cover increased gradually. According to the observations, the temperature gradient in the top $80 \mathrm{~cm}$ of the snow cover decreased from $0.064 \mathrm{~K} / \mathrm{cm}$ on 15 February to $0.049 \mathrm{~K} / \mathrm{cm}$ on 15 March. During this period, the transport of water vapour diminished, and the temperature gradient for metamorphism in the snow was discontinuously replaced by a regime for melting-regelation metamorphism. In most cases, the thickness of the depth hoar reached more than $80 \%$ of the total thickness of the snow cover, and the snow temperature became $0^{\circ} \mathrm{C}$ from its surface to bottom at the end of March or the beginning of April (Hu Ruji and Wei Wenshou, 1987).

Besides its weakness, depth hoar also has a small water capacity, and it is very easy for melt water derived from the snow surface to penetrate from the surface to the bottom of the snow cover. In addition, the bonds between the grains of the depth hoar melt at first, and thus the snow cover becomes loose and release of an avalanche becomes easy. That is one of the reasons for depth-hoar full-depth avalanches occurring frequently in the western
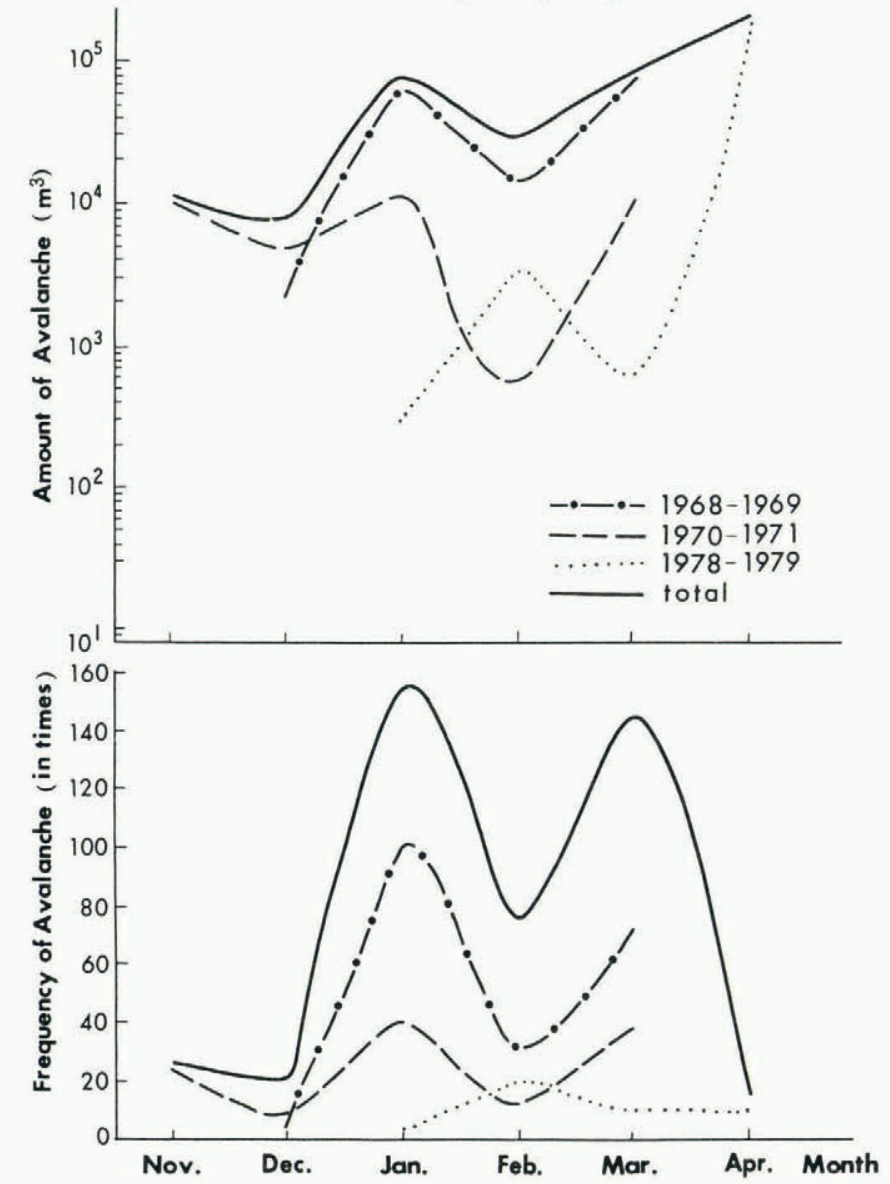

Fig. 4. Inter-annual and monthly variations of amount and frequency of avalanches during the snow season near TSAR station. part of the Tian Shan mountains during the snow-melt season (Fig. 4).

\section{RELATIONSHIP BETWEEN DEPTH HOAR AND AVALANCHE RELEASE}

The thickness of the snow cover in the western part of the Tian Shan mountains is less than that of the snowy region in south-west China. However, depth hoar, which provides very good conditions for avalanche release, develops extraordinarily well in the Tian Shan mountains. If there is snowy weather or the air temperature increases quickly, avalanches will occur frequently. Of course, avalanches are also determined by precipitation during the snow season. For example, the thickness of depth hoar comprised $70 \%$ of the total snow-cover depth on 12 February 1983, but even so avalanches occurred only once on a few of the avalanche routes. However, avalanches occurred twice on some of the avalanche routes, and even three or four times on some other routes in the snow season of 1987-88 when the precipitation was almost twice as much as that in 1982-83 (Hu Ruji and others, 1978) (Fig. 5), but the thickness of depth hoar comprised only $43 \%$ of the total snow cover.
(A) February 10, 1988

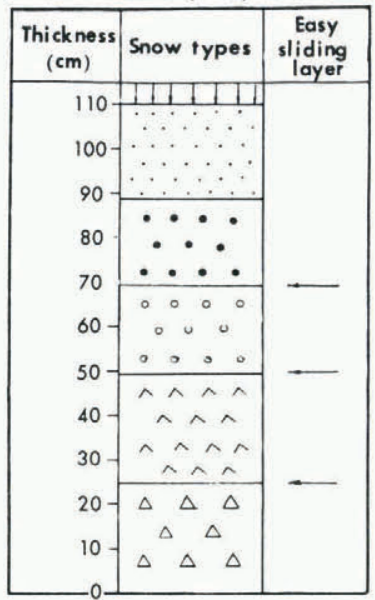

I.IT) Fresh snow

$\therefore$ Fine-grained snow

$\because$ Medium-grained snow
(B) February 12,1983

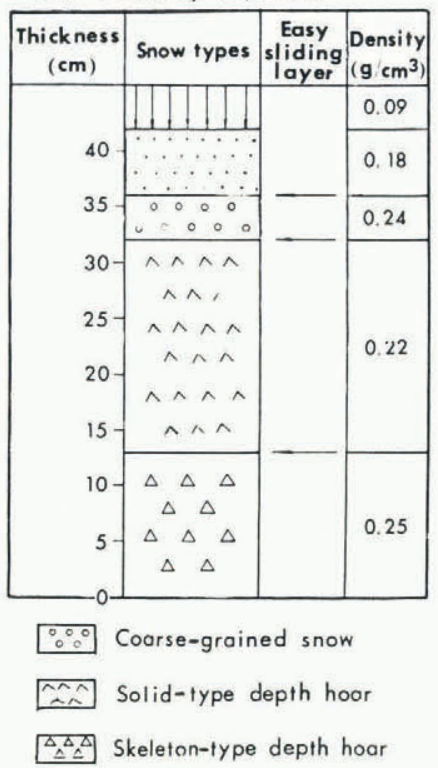

Fig. 5. Comparison of two stratigraphic sections of snow cover observed in 1983 and 1988.

\section{CONCLUSION}

In the western part of the Tian Shan mountains, there is an abundance of material for the development of depth hoar by much solid precipitation during the snow season, and the large temperature gradient in the snow cover is caused by the low air temperature and high ground temperature; hence the excellent conditions for the development of depth hoar are provided by a large temperature gradient and a long period of negative temperatures. The frequent avalanche occurrences are caused only by no more than a $50 \mathrm{~cm}$ thickness of snow cover with a thick depth hoar, snowy weather, and the rapid increase in air temperature. These are the main reasons why avalanches occur frequently under conditions of limited snow cover in the mid-mountain zone of the western Tian Shan mountains.

\section{ACKNOWLEDGEMENTS}

This study was supported by the Tian Shan Snow and Avalanche Research Station. The authors are grateful to Professor Bai Zhongyuan, Lanzhou Institute of Glaciology and Geocryology, Academia Sinica, for his valuable advice and help in completing this paper, to $\mathrm{Mr}$ Jiang Fengqing and $\mathrm{Mr}$ Wang Guo for their co-operation, and to $\mathrm{Mr}$ Yin $\mathrm{Jie}$ and $\mathrm{Mr}$ Wei Xingjun for their assistance in the field observations. The authors would also like to thank Mrs Zhu Guocun for her preparation of the illustrations. 


\section{REFERENCES}

Hu Ruji and Wei Wenshou. 1987. On the zoning of snow damage in China. [In Chinese.] J. Glaciol. Geocryol., 9, Special Issue, 1-12.

$\mathrm{Hu}$ Ruji, and others. 1985. On basic characteristic of seasonal avalanche on mountains, Xinjiang. Arid Land Geography, 8(1), 53-57.
$\mathrm{Hu}$ Ruji, Ma Weilin, and Wang Cunnin. 1987. Avalanches in Tianshan Mountains, China, and their control. [In Chinese.] J. Glaciol. Geocryol., 9, Special Issue, 13-24.

Ma Weilin. 1981. Cause of avalanche formation and analysing of avalanche characteristic near the Tianshan Snow and Avalanche Research Station in winter of 1978 to 1979. Xinjiang Geography, 4(2), 41-47.

Revised MS. received 19 December 1988 